\title{
Periodização do Treinamento e da Nutrição Esportiva
}

- O Colégio Norte Americano de Medicina do Esporte, define atividade física como o movimento corporal que é produzido pela contração dos músculos esqueléticos, levando a um aumento do gasto energético;

- Já o exercício, é definido como o movimento repetitivo, planejado e estruturado para melhorar, ou manter um ou mais componentes da aptidão física (força, potência, resistência e/ou flexibilidade). A definição do exercício nos leva a interpretar que se o indivíduo não tem um planejamento, ele não está efetivamente realizando exercício, mas sim apenas atividades físicas;

- No processo do treinamento esportivo, prescrevemos programas de exercícios e, por isso, temos planejamentos de treino, cuja elaboração e organização engloba processos como a avaliação das capacidades físicas, elaboração das sessões e o controle e monitoramento das cargas de treino;

- A periodização do treinamento é uma forma de divisão de um planejamento em períodos. Ela possui uma sequência lógica de alteração das variáveis do treinamento (i.e. intensidade, volume, pausas, etc.) e objetiva aumentar o desempenho para objetivos específicos. Adicionalmente, visa minimizar o potencial overtraining e as lesões, incorporando períodos de recuperação ao longo do planejamento;

- São características básicas de um planejamento de treinamento: 1) ser designado de acordo com os principais objetivos de desempenho para a temporada; 2) ter as cargas progressivamente aumentadas; 3 ) as fases do treinamento seguirem uma sequência lógica de aplicação de estímulos; 4) estratégias de recuperação são intensivamente utilizadas ao longo do planejamento; 5) cada fase do treinamento é construída de acordo com a base previamente formada;

- A interação entre exercício, respostas adaptativas e disponibilidade de nutrientes é bem reconhecida e consolidada na literatura, sendo as adaptações ao treinamento podendo ser amplificadas pela qualidade e quantidade de nutrientes consumidos nos períodos pré e pós exercícios;

- Entretanto, como efetivamente essa alteração no suprimento energético pode modificar as respostas adaptativas, ainda vem sendo uma grande área de pesquisa conduzida por várias décadas;

- Dependendo das modalidades esportivas praticadas, uma variedade de estratégias nutricionais podem ser utilizadas para otimizar aspectos fisiológicos e bioquímicos que possam limitar o desempenho e causar a fadiga. Essas incluem um adequado fornecimento de substratos energéticos e de hidratação;

- Tal forma de manipulação das específicas estratégias nutricionais a serem utilizadas é atualmente chamada na literatura de Periodização Nutricional. Ela objetiva combinar estratégias de treinamento físico e nutricionais, ou somente as nutricionais para levar a determinadas adaptações que otimizem o desempenho físico e/ou adaptações morfológicas ao treinamento;

- No recente artigo "Periodized Nutrition for Athletes", publicado pelo pesquisador Asker Jeukendrup, são apresentados alguns métodos de periodização nutricional mais comuns em relação a manipulação da disponibilidade de macronutrientes e o uso de suplementos. Dentre eles, as estratégias chamadas de "training low" (treinar com baixa disponibilidade de carboidratos), "training high" (treinar com alta disponibilidade de carboidratos) e combinações de "training low e training high". Especificamente o "training low" é a mais estudada e a que possui mais propostas de variações. 
- Considerando que as alterações no tipo, intensidade e volume dos treinamentos, claramente criam as principais diferenças na requisição por carboidratos, proteínas, fluídos e alguns micronutrientes, para que o nutricionista esportivo consiga elaborar um bom planejamento alimentar, ele deve ter acesso ao planejamento de treino físico de seus pacientes/atletas.

- A análise desses dados fornecerá a base para o planejamento nutricional, implicando que o nutricionista esportivo deva saber interpretar os métodos de treinamento físico e a manipulação de variáveis como o volume, intensidade, adaptações e predomínio metabólico dos treinamentos aplicados;

- Tal interpretação, pode auxiliar na prescrição do plano alimentar no tocante a requisição por carboidratos, proteínas, fluídos e alguns micronutrientes ao longo das etapas do planejamento.

\section{Referências bibliográficas}

1. BURKE, L.M. et al. Toward a Common Understanding of Diet-Exercise Strategies to Manipulate Fuel Availability for Training and Competition Preparation in Endurance Sport. International Journal of Sport Nutrition and Exercise Metabolism; 28(5):451-463, 2018.

2. DEWEESE, B. et al. The training process: Planning for strength-power training in track and field. Part 1: Theoretical aspects. Journal of Sport and Health Science; 4(Issue 4):308-317, 2015.

3. DEWEESE, B. et al. The training process: Planning for strength-power training in track and field. Part 2: Practical and applied aspects. Journal of Sport and Health Science; 4(Issue 4):318-324, 2015.

4. HAWLEY, J.A.; MAUGHAN, R.J.; HARGREAVES, M. Exercise Metabolism: Historical Perspective. Cell Metabolism; 22(1):12-17, 2015.

5. ISSURIN, V.B. New horizons for the methodology and physiology of training periodizationSports Medicine, 2010.

6. JEUKENDRUP, A.E. Periodized Nutrition for AthletesSports Medicine, 2017.

7. KRAEMER, W.J. et al. American College of Sports Medicine position stand. Progression models in resistance training for healthy adults. Med Sci Sports Exerc; 34(2): 364-380, 2002.

8. MUJIKA, I. et al. An Integrated, Multifactorial Approach to Periodization for Optimal Performance in Individual and Team Sports. International Journal of Sports Physiology and Performance; 13(5): 538-561, 2018. 